\title{
Murcha por Ceratocystis em eucalipto: avaliação de resistência e análise epidemiológica
}

\author{
Karina Goulart Tumura ${ }^{1^{*}}$; Cristiane De Pieri ${ }^{1}$; Edson Luiz Furtado ${ }^{2,3}$
}

${ }^{1}$ Programa de Pós Graduação em Ciência Florestal; ${ }^{2}$ Departamento de Defesa Fitossanitária, Faculdade de Ciências Agronômicas, Universidade Estadual Paulista, CP 237, 18603-970, Botucatu-SP; ${ }^{3}$ Bolsista CNPq. *Parte da Dissertação de Mestrado do primeiro autor Autor para correspondência: Edson Luiz Furtado (elfurtado@fca.unesp.br)

Data de chegada: 10/11/2010. Aceito para publicação em: 02/02/2012.

\section{RESUMO}

Tumura, K.G.; De Pieri, C.; Furtado, E.L. Murcha por Ceratocystis em eucalipto: avaliação de resistência e análise epidemiológica . Summa Phytopathologica, v.38, n.1, p.54-60, 2012.

A cultura do eucalipto é uma das mais importantes do Brasil, constituindo-se em fonte de energia e madeira renovável, além de suportar importantes processos agroindustriais para produção de celulose, papel e essências. O eucalipto, como outras espécies vegetais, é infectado por diversos patógenos, principalmente fungos, desde o viveiro até plantios adultos. Neste trabalho, foi estudado o agente causador da murcha de Ceratocystis. Trata-se de um típico patógeno de xilema (Ceratocystis fimbriata Ellis et. Halsted), cujo sintoma marcador é constatável nas secções transversais de órgãos lenhosos, na forma de estrias radiais escuras, da medula para o exterior do lenho ou da periferia do lenho para a medula ou descoloração (mancha escura) do tipo cunha em geral da periferia para a medula. Essas estrias no lenho são visíveis quando um ramo afetado é cortado transversalmente, pois o patógeno provoca a desintegração do sistema vascular. Trata-se de um fungo de rápida disseminação e que atinge plantas em diversos estágios de desenvolvimento, sendo por isso de difícil controle. Os objetivos deste estudo foram verificar a suscetibilidade de clones visando encontrar material resistente e estudar a epidemiologia da doença em campo. Para isso, utilizaram-se mudas de clones operacionais para inoculação do patógeno para avaliação de resistência; a avaliação epidemiológica foi feita de acordo com levantamentos de campo em parcela previamente instalada. Foram encontrados materiais com diversos níveis de resistência, desde altamente resistente até a altamente suscetível. Em campo, a doença apresentou distribuição espacial agregada, com tendência a agregação de focos e distribuição vertical (na linha de plantio).

Palavras-chave adicionais: murcha, eucalipto, resistência, epidemiologia

\section{ABSTRACT}

Tumura, K.G.; De Pieri, C.; Furtado, E.L. Ceratocystis wilt in eucalyptus: Evaluation of resistance and epidemiological analysis. Summa Phytopathologica, v.38, n.1, p.54-60, 2012.

The cultivation of eucalyptus is one of the most important in Brazil, constituting a source of renewable energy and wood, supporting important agro-industrial processes for production of pulp, paper and essences. Eucalyptus, like other plant species is infected by various pathogens, especially fungi, from nursery to adult trees. In this work, was studied de causative agent of Ceratocystis wilt. The fungus Ceratocystis fimbriata Ellis. et Halsted is a typical xylem pathogen, which the marker symptom is observable in the cross sections of woody organs in the form of dark radial striations, from core to the outer periphery of the wood or from the periphery to the core. These streaks in the wood are visible when an affected branch is cut across because pathogen causes the disintegration of the vascular system. It is a fungus of fast spreading and that affects plants in various stages of development and because of this is difficult to control. The objectives of this work were verify the clonal susceptibility to the pathogen for aid breeding programs to obtain resistant materials and study epidemiological model for determination of disease progress on the field. For this, stecklings of operational clones were used for inoculation to evaluate the resistance. Epidemiological assessment of spatial distribution was made according to field surveys with plots previously installed. Different resistance levels were found in the studied materials, since high resistance until high susceptibility. In the field, the disease showed a clustered distribution, with tendency to aggregation of foci and vertical distribution (in the plant line).

Keywords: wilt, eucalyptus, resistance, epidemiology

A cultura do eucalipto vem assumindo cada vez mais um papel importante na economia nacional. O setor brasileiro de celulose e papel é composto por cerca de 222 empresas localizadas em 539 municípios, em 18 Estados, em todas as regiões do país. As exportações do setor atingiram o valor de US\$ 5 bilhões e têm um saldo comercial de US\$ 3,7 bilhões, cerca de 14,4\% da balança comercial brasileira (1). Tendo em vista sua importância econômica, é vital controlar qualquer fator que venha a interferir no processo de produção da cultura do eucalipto, seja ele de origem abiótica ou biótica.

O eucalipto, como outras espécies vegetais, é infectado por diversos patógenos desde o viveiro até plantios adultos. Dentre esses, destacase o fungo Ceratocystis fimbriata Ellis \& Halsted, causador de murchas e cancros. (12). A murcha é um sintoma complexo que pode ter diferentes causas, dentre elas a descontinuidade na translocação pelo 
xilema da água absorvida pelas raízes. O colapso desse sistema de transporte em função de sua colonização por agentes patogênicos impede o fluxo normal da seiva bruta através dos vasos do xilema, levando a planta à morte.

Ceratocystis fimbriata Ellis \& Halsted causa doenças em muitas plantas lenhosas de importância econômica como, por exemplo, a acácia negra, o cacau, o café, a mangueira, a seringueira e o eucalipto (38). Pertencente à classe Pyrenomycetes, ordem Ophiostomatales, subdivisão Ascomycotina, produz peritécios negros, eruptivos, providos de conspícuo rostro. Os ascósporos são unicelulares, hialinos e são liberados em massa gelatinosa. Microconídios hialinos são produzidos no interior dos conidióforos, ao passo que os macroconídios pigmentados são produzidos nas extremidades destes (38).

O fungo causador da murcha de Ceratocystis pode penetrar na planta através de ferimentos, diretamente pelas raízes (15) e pela epiderme através de um inseto vetor (microcoleópteros - Coleoptera: Nitidulidae). Essa relação inseto-fungo é facilitada pelo fato da maioria das espécies de Ceratocystis produzirem aromas que atraem os insetos (4). Trata-se de um típico patógeno de xilema, que tem seu desenvolvimento inicial no câmbio, entre a casca e o lenho. Um de seus sintomas típicos é visível nas secções transversais de órgãos lenhosos, na forma de estrias radiais escuras (3). Essas estrias no lenho são visíveis quando um ramo afetado é cortado transversalmente, pois o patógeno provoca a desintegração do sistema vascular da planta (15). O escurecimento dos vasos é atribuído ao transporte de substâncias resultantes da oxidação e polimerização de compostos fenólicos. Os sintomas da murcha surgem em consequiência do bloqueio dos vasos pelo crescimento micelial do fungo, impedindo que a água absorvida pelo sistema radicular supra adequadamente a parte aérea da planta. Em ambientes favoráveis ao desenvolvimento da doença, a planta morre e o fungo passa a crescer no tecido em decomposição sobre o qual realiza sua reprodução através da formação de esporos e estruturas de resistência (clamidósporos) (7).

Em campo podem ser observados dois padrões de murcha: um deles com início nos ramos finos da copa e que progride em direção ao tronco, matando a árvore lentamente; o outro começa pelas raízes e a planta morre repentinamente, muitas vezes sem apresentar os sintomas típicos da doença (16). Quando o adensamento das estrias radiais escuras toma toda a circunferência interna do lenho das raízes ou da base do tronco, ocorre a inativação do xilema e a árvore morre. Se a inativação do xilema ocorrer em uma altura elevada do tronco principal, se tem a murcha e a subseqüente morte do segmento terminal, havendo, por isso, alteração do balanço hormonal, resultando na emissão de brotações adventícias em setores medianos e basais do tronco (14, 15). Quando se tem morte do setor apical em conseqüência de estresse hídrico em alguma árvore já infectada por C. fimbriata, o avanço do patógeno, ascendentemente, é muito rápido, observando-se gradativo aumento de adensamento das estrias radiais escuras nas secções, no sentido base-ápice.

A doença foi relatada pela primeira vez no Brasil em dezembro de 1997, em reflorestamentos clonais no sudeste da Bahia $(12,11)$, onde se observaram talhões monoclonais de híbridos E. urophylla x $E$. grandis com mortalidade de plantas superior a $40 \%$. No primeiro ano de observação da doença, verificou-se que ela se limitava a plantações monoclonais de dois genótipos. Após esse período, constatou-se a doença em mais três genótipos, sendo esses cinco genótipos, clones nobres dos pontos de vista silvicultural e tecnológico. Depois, constatou-se em hastes de brotações do banco clonal destinadas ao enraizamento de estacas, em estacas de enraizamento dentro da casa de vegetação e em mudas já enraizadas na fase de aclimatação, no viveiro e a céu aberto (13). Posto isso, pode-se inferir que existe grande risco de introdução da doença em áreas livres do patógeno via mudas propagadas vegetativamente. A partir de 2001, relatou-se a ocorrência da doença em plantios monoclonais também nos Estados de Mato Grosso do Sul, Bahia, Minas Gerais e de São Paulo (13).

O Brasil e o Uruguai foram os únicos países das Américas onde foi constatada a murcha de Ceratocystis em eucalipto. Adoença foi também registrada em Uganda, República do Congo e África do Sul. Os isolados congoleses foram agrupados filogeneticamente com os isolados brasileiros de eucalipto, isolados de Acacia mearnsii de Wild. da África do Sul e de isolados de batata doce dos Estados Unidos e de Papua Nova Guiné. Já os isolados da África do Sul foram agrupados aos isolados de eucalipto da África e da América do Sul $(34,36,35)$. Pode ser observada uma especialização do patógeno em relação ao hospedeiro e entre os isolados brasileiros, pois os isolados do eucalipto aparentemente são patogênicos somente ao eucalipto $(2 ; 41)$.

Do ponto de vista epidemiológico, as doenças de plantas podem ser classificadas em: juros composto ou de juros simples (39) e poliéticas (40). A murcha do eucalipto causada por Ceratocystis fimbriata é considerada uma doença poliética, ou seja, o progresso da epidemia se verifica ao longo dos anos. A partir dessa afirmação, existem estudos de análise de dinâmica e estrutura de focos (ADEF) que foram desenvolvidos para caracterizar espacialmente epidemias, cujas avaliações são baseadas na incidência. Assim, um foco de doença é definido como árvores com sintomas imediatamente adjacentes no padrão de proximidade vertical, horizontal ou diagonal (30). O foco de doença é definido como um ponto de concentração localizada de plantas doentes ou lesões discretas, podendo ser uma fonte primária de infecção ou coincidir com uma área originalmente favorável ao estabelecimento da doença (30) e tendem a influenciar no padrão posterior de transmissão da doença. Similarmente, um grupo pode ser definido como um número de plantas doentes agrupadas, entretanto, apesar dos dois termos serem sinônimos é interessante entender que um foco de doença pode consistir de uma única planta doente e um grupo, por sua vez, prediz uma ou mais de uma planta doente $(30,23)$.

Pelo método da ADEF é possível caracterizar um número razoável de variáveis importantes no patossistema, tais como: número de focos com plantas doentes, número de focos unitários, a forma do foco, o número médio de plantas por foco e o índice de compactação do foco. Essas variáveis podem ser estudadas em função da incidência da doença e poderá contribuir nas informações oriundas de outras técnicas de análise espacial $(30,31)$. As variáveis da ADEF podem ser empregadas para complementar as informações oriundas de outras técnicas de análise espacial (21) e visa um melhor entendimento do patossistema.

O padrão espacial de uma doença numa linha de plantio ou numa parcela pode ser ao acaso ou agregado. Padrão ao acaso em doenças cujos patógenos são veiculados pelo ar significa que a probabilidade de um esporo cair sobre uma planta hospedeira é igual para todas as plantas hospedeiras. Assim, a ocorrência da doença não é influenciada pela distância até a fonte de inóculo, seja a fonte localizada na mesma planta ou na vizinhança próxima. Padrão espacial ao acaso está intimamente relacionado a iguais oportunidades de infecção. Se, no entanto, em condições naturais, o patógeno se dispersa apenas a curtas distâncias (por respingos de chuva, por exemplo), a probabilidade de uma planta ser infectada é maior para aquelas plantas situadas próximas à fonte de inóculo do que para aquelas situadas longe da fonte de inóculo. Neste caso, o padrão espacial da doença não será ao acaso e, sim, agregado, com focos visíveis ao redor das fontes primárias de inóculo. Agregação é apenas um dos possíveis desvios para o padrão 
espacial ao acaso ou aleatório.

Tendo em vista a importância da murcha por Ceratocystis para a cultura do eucalipto, os objetivos deste estudo foram verificar a suscetibilidade de clones visando encontrar material resistente e estudar a epidemiologia da doença em campo.

\section{MATERIAL E MÉTODOS}

\section{Testes de resistência clonal}

Receberam-se mudas de duas procedências distintas, totalizando 37 clones, aqui denominados clones 1 a 37, com dez mudas de cada um, sendo que para uma das procedências foram recebidos dois lotes diferentes de mudas, em períodos distintos. Todos os materiais tinham quatro meses de idade. Primeiramente, foram avaliados 18 clones e, em um segundo momento, os 19 restantes.

O método de inoculação usado foi o do disco de micélio no qual, com o auxílio de um escalpelo fez-se um ferimento a, aproximadamente, $10 \mathrm{~cm}$ do colo da muda, da casca até o lenho, onde foi colocado o disco com micélio do fungo, fazendo-se uma câmara úmida com algodão embebido em água destilada para vedar a lesão. Para a inoculação utilizou-se um isolado patogênico ao eucalipto, obtido através do isolamento de plantas doentes de eucalipto oriundas de Minas Gerais em meio de cultura BDA (batata - dextrose - ágar).

Passados 30 dias da inoculação, realizou-se a avaliação das mudas, de maneira destrutiva, medindo-se o tamanho da lesão escurecida ao longo do caule da muda e também os outros sintomas apresentados ou se as mesmas estavam mortas. Os materiais de cada lote foram classificados em altamente resistente (AR), moderadamente resistente (MR), moderadamente suscetível (MS), suscetível (S) e altamente suscetível (AS) de acordo com a distribuição de frequência do tamanho da lesão longitudinal. Não houveram mudas deixadas como testemunha.

Após a avaliação, mudas apresentando os diferentes padrões (assintomáticas, com amarelecimento de copa e morta) foram escolhidas aleatoriamente para serem submetidas ao isolamento do fungo em meio de cultura para constatação do agente causal da murcha.

Avaliação espacial (análise de dinâmica e estrutura de foco)

A avaliação espacial foi realizada em parcela experimental de 250 plantas localizada em Três Lagoas/MS. Os dados foram obtidos a partir dos levantamentos previamente realizados pelo corpo técnico da empresa a cada seis meses. Foi contabilizada a incidência de plantas sadias e doentes, considerando-se como doentes todas as plantas que apresentaram os sintomas típicos da doença, tais com desfolha intensa, presença de canelura e rachaduras na base tronco e superbrotação ao longo do fuste.

Os cálculos da distribuição espacial e estrutura de foco da parcela experimental foram feitos através de software desenvolvido por Porcena (2008, não publicado). O software foi rodado em Sistema Operacional GNU/Linux usando a distribuição OpenSuse e foi compilado em GCC usando a IDE Eclipse, o código fonte utilizado é o mesmo compilado em Windows.

\section{Análise de dinâmica e estrutura de foco (ADEF)}

A murcha do eucalipto causada por Ceratocystis fimbriata é considerada uma doença poliética, ou seja, o progresso da epidemia se verifica ao longo dos anos. A partir dessa afirmação, existem estudos de dinâmica e estrutura de focos, através de planilhas de campo, os quais se fundamentam no número total de ocorrência de focos (NF), focos unitários (FU), número médio de plantas por foco (NMPF), índice de compactação do foco (ICF) e índice de formação de foco (IFF). Com essa verificação o estudo desempenhará um papel fundamental no processo de dispersão da doença e estrutura de focos, permitindo possivelmente correlacionar esta dispersão a diversos fatores adversos.

No estudo da estrutura dos focos da murcha de Ceratocystis em clones de eucalipto foi quantificado o índice médio de forma de focos (IFF) e o índice médio de compactação de focos (ICF), através das equações:

\section{$\cdot \mathbf{I F F}=[(\mathbf{l f} / \mathbf{l c}) / \mathbf{N F})]$}

Onde:

IFF = índice médio de forma de focos

If = número máximo de linhas ocupadas no foco

lc = número máximo de colunas ocupadas no foco

$\mathrm{NF}=$ número total de ocorrência de focos

Em que:

Valores de IFF $=1,0$ indicam focos isodiamétricos.

Valores de IFF > 1,0 indicam focos com maior comprimento na direção entre as linhas de plantio.

Valores de IFF $<1,0$ indicam focos com maior comprimento na direção da linha de plantio.

\section{$\cdot \mathbf{I C F}=[(\mathbf{N P F} / \mathbf{l} * \mathbf{l f}) / \mathrm{NF}]$}

Onde:

ICF = índice médio de compactação de focos

If = número máximo de linhas ocupadas no foco

lc = número máximo de colunas ocupadas no foco

$\mathrm{NF}=$ número total de ocorrência de focos

Em que:

Valores de ICF próximos a 1,0 indicam focos mais compactos, isto é, maior agregação e proximidade entre todas as plantas pertencentes ao foco.

A partir desses dados, pode-se inferir sobre o processo de dispersão da doença com a possibilidade de obter conclusões favoráveis, visando o estudo de melhoramento da espécie voltada à produção.

\section{Dinâmica espacial - índice de dispersão}

A análise do padrão espacial da murcha de Ceratocystis foi realizada através de mapeamento da parcela experimental a partir de dados binários (presença ou ausência de árvores doentes). Foram contabilizadas como árvores doentes as que apresentaram os sintomas típicos da doença e calculou-se a incidência da mesma em cada data de avaliação com a seguinte fórmula: $(p=T / D)$. Em que: $\mathrm{T}=$ número total de árvores na parcela; $\mathrm{D}=$ número total de árvores doentes.

Os dados de incidência formaram a base para o cálculo do índice de dispersão (ID) $(17,27,25,24)$. Cada mapa foi dividido em dois tamanhos de quadrats de 4 (2x2) e 10 (5x2) árvores/quadrat. Para cada mapa e tamanho de quadrat foi realizada uma análise individual.

A análise da distribuição das árvores com murcha dentro dos quadrats, em cada avaliação, foi estimada pela análise binomial, através do cálculo do índice de dispersão binomial, que é a (Vobs) variância observada entre quadrats e a (Vbin) variância da distribuição binomial (28).

Para cada uma das avaliações e para cada tamanho de quadrat, a análise binomial (planta doente ou sadia) foi calculada na forma de variância observada $($ Vobs $)(28,29)$ em que: Vbin $=p(1-p) / n$ onde: $p$ = incidência da doença na parcela $\mathrm{n}=$ número de árvores no quadrat Vobs $\left.=\sum(\mathrm{xi}-\mathrm{n} \mathrm{p})^{2} / \mathrm{n}^{2}(\mathrm{~N}-1)\right]$ onde: $\mathrm{Xi}=$ número de árvores doentes no quadrat e $\mathrm{N}=$ número total de quadrats.

Para o cálculo do índice de dispersão (ID) utilizaram-se os resultados 
da Vobs/Vbin, sendo possível concluir, sobre o padrão de distribuição espacial das árvores doentes em cada mapa e para cada quadrat.

Para os valores de ID obtidos de cada quadrat foi aplicado o teste do $\chi^{2}$ (qui-quadrado) para verificar se o valor calculado foi maior ou igual a 1 a nível de significância de $5 \%$.

\section{RESULTADOS E DISCUSSÃO}

\section{Testes de resistência clonal}

A maioria dos clones apresentou resistência moderada, sendo que somente um apresentou suscetibilidade ao patógeno. Todas as mudas foram submetidas a avaliação destrutiva para averiguação de seu sistema vascular, inclusive as que permaneceram assintomáticas, comportamento que também é observado em campo e dificulta a diagnose da doença. Contabilizaram-se também as mudas mortas, porém estas não ocorreram em grande quantidade (Figura 1).

A avaliação do sintoma marcador da doença foi feita através da medição longitudinal da lesão escurecida no lenho do caule da muda. Mais trabalhos são necessários para se determinar a idade ideal para avaliação da resistência à murcha de Ceratocystis, contudo a descoloração do xilema, muito mais que a mortalidade, vem se apresentando como um parâmetro melhor para avaliação da resistência e suscetibilidade (2).

Houve uma variação substancial no comprimento da descoloração do xilema entre os clones de cada lote, onde para o lote 1 , o tamanho da lesão variou entre 2,17 a $8,17 \mathrm{~cm}$; para o lote 2 a variação foi de 0,73 a $6,70 \mathrm{~cm}$ e para o lote 3 , de 0,88 a $2,53 \mathrm{~cm}$. Os materiais foram alocados em cinco classes de resistência através de distribuição de frequência de acordo com o tamanho da lesão, obtendo-se as seguintes porcentagens para cada uma delas: $10,81 \%$ de clones altamente resistentes; $72,97 \%$ de clones moderadamente resistentes; $13,51 \%$ de clones moderadamente suscetíveis; e $2,70 \%$ de clones suscetíveis (Figura 2).

Os resultados obtidos nos testes de resistência foram semelhantes aos atingidos por Machado et al. (26), nos quais os autores testaram a resistência interespecífica do eucalipto, obtendo como resposta uma maioria de clones moderadamente resistentes.

Os estudos para resistência a murcha de Ceratocystis estão em fase incial. Resistência a esse mesmo fungo foi detectada em cacau (Theobroma cacao) e Coffea arabica e se mostrou altamente valiosa para o manejo da doença $(10,20,42)$. No Brasil, a doença causou mortalidade substancial em apenas alguns clones de híbridos de E. grandis X E. urophylla (13). Porém, deve ser ressaltado que esses materiais são de alta qualidade silvicultural e possuem características superiores, como por exemplo, teor de celulose e crescimento rápido, o que passa ser um problema, tendo em vista que uma das recomendações de controle é a não utilização de materiais suscetíveis em áreas onde se sabe que o patógeno é encontrado.

Além da utilização de clones resistentes, que é a opção mais efetiva de controle, o manejo da doença pode incluir: a remoção e destruição das plantas infectadas, diminuição nos ferimentos, pois o patógeno pode colonizar a planta através deles e rotação de culturas com plantas que não sejam hospedeiras do patógeno. A doença também pode ser disseminada para novas áreas através de cepas doentes e cuidados devem ser tomados para que a doença não seja disseminada por material propagativo.

\section{Avaliação espacial (análise de dinâmica e estrutura de foco) Análise de dinâmica e estrutura de foco}

No Brasil, a técnica da ADEF foi utilizada em estudos na citricultura como: (i) a clorose variegada dos citros (CVC), Xylella fastidiosa, que apresentou um padrão de dispersão levemente agregado (12); (ii) testes de diagnose da CVC pelos métodos de sintomas e por sorologia DIBA PCR (32); (iii) diferenças dos padrões espaciais das plantas com cancro cítrico na presença ou ausência da larva minadora do citrus (Phyllocnistis citrella Stainton) $(5,8)$ e (iv) morte súbita dos citros (MSC) em pomares do norte de São Paulo e sul do Triângulo Mineiro (21). Para a cultura do eucalipto, a técnica da ADEF foi utilizada nos estudos da ferrugem causada por Puccinia psidii (29), do cancro basal causado por Crysophorte cubensis (37) e da seca de ponteiros em Corymbia citriodora causada por Botryosphaeria ribis/ Dothiorella sp. (9). Deve-se ressaltar que ainda existem poucos estudos para a cultura do eucalipto, bem como outras culturas utilizando-se a técnica da ADEF.

No estudo da estrutura dos focos da murcha de Ceratocystis, foi quantificado o índice médio de forma de focos (IFF) e o índice médio de compactação de focos (ICF) (tabela 1).

Os valores do índice de forma de focos (IFF), quando analisados em conjunto para as três avaliações, apresentaram-se em um grupo com IFF menores que 1 , indicando que a murcha de Ceratocystis

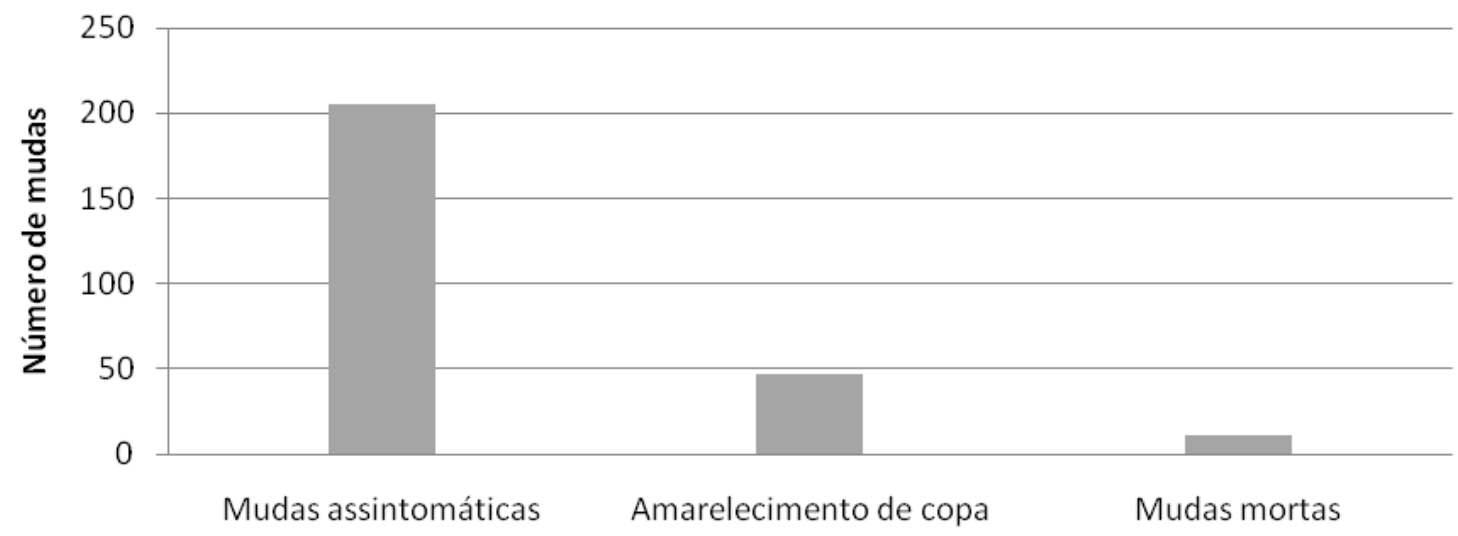

Características observadas nas mudas avaliadas

Figura 1. Quantificação de sintomas da murcha por Ceratocystis em mudas clonais de eucalipto 


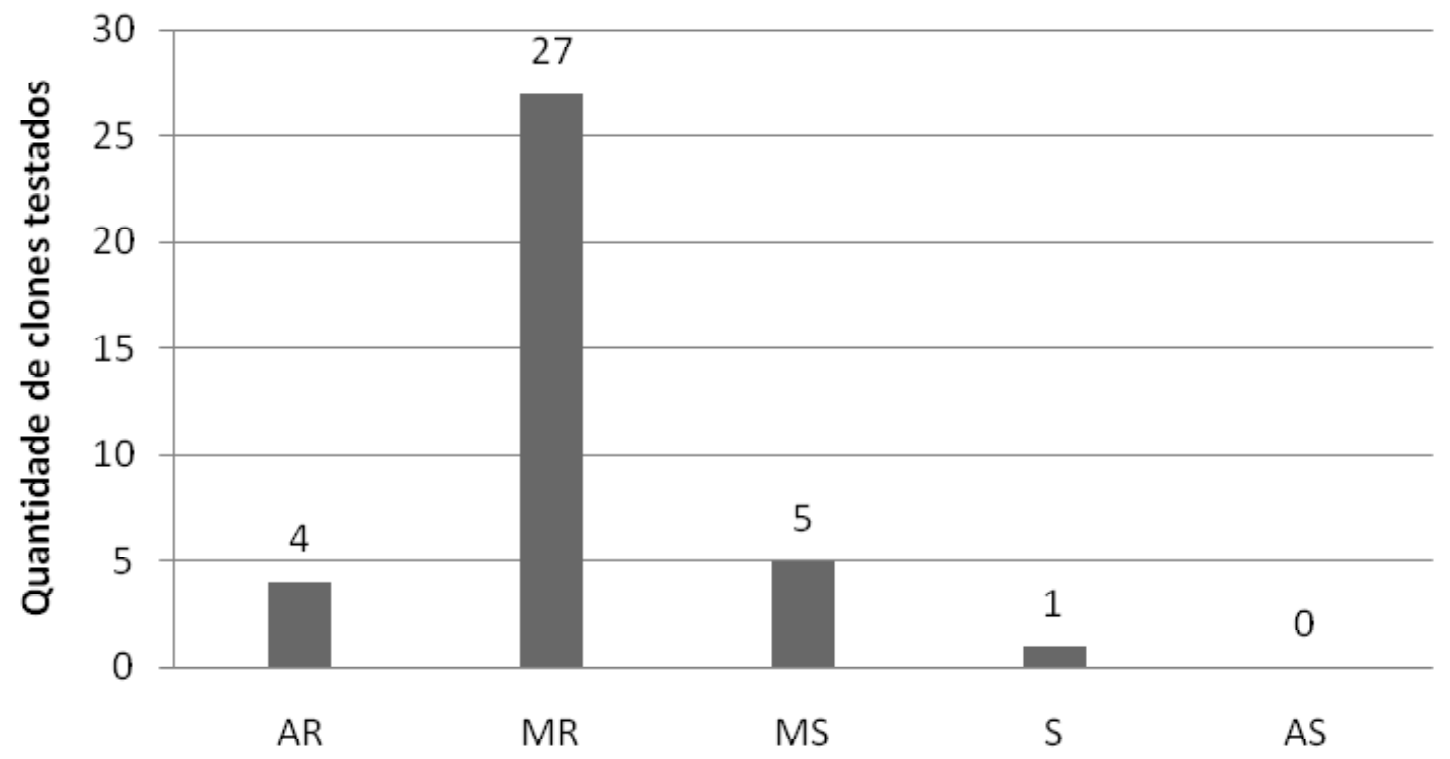

\section{Classe de resistência}

Figura 2. Distribuição da frequência de classes de resistência apresentada pelos clones 1 a 37, contemplando os três lotes de mudas avaliados, onde: AR - altamente resistente; MR - moderadamente resistente; MS - moderadamente suscetível; S - suscetível; AS - altamente suscetível)

Tabela 1. Análise da dinâmica e estrutura de focos da murcha por Ceratocystis na região de Três Lagoas/MS

\begin{tabular}{|c|c|c|c|c|c|c|c|}
\hline AVALIAÇ ÇO & INCIDÊNCIA (\%) & NPD & $\mathbf{N F}$ & NFU & NMPF & IFF & ICF \\
\hline 1 (Janeiro/2009) & 10,77 & 28 & 14 & 8 & 2 & 0,77 & 1,01 \\
\hline 2 (Agosto/2009) & 13,08 & 34 & 17 & 10 & 2 & 0,83 & 1,18 \\
\hline 3 (Janeiro/2010) & 25,71 & 72 & 17 & 6 & 4,24 & 0,80 & 1,08 \\
\hline
\end{tabular}

Onde:

NPD = número de plantas doentes

$\mathrm{NF}=$ número de focos

$\mathrm{NMPF}=$ número médio de plantas por foco

$\mathrm{NFU}=$ número de focos unitários $\quad \mathrm{ICF}=$ índice de compactação de focos

ocorreu em distribuição vertical na direção da linha de plantio, sugerindo haver crescimento maior do número de plantas doentes nas linhas ocupadas pelo foco, em detrimento do crescimento do foco e do número de linhas. Esse resultado assemelha-se ao obtido por Souza (37) no estudo da distribuição espacial do cancro basal do eucalipto.

A dinâmica e estrutura de focos $\mathrm{ADEF}$ da murcha de Ceratocystis em clones de eucalipto permite conhecer o modo como ocorre o desenvolvimento espacial da doença. Os resultados obtidos parecem indicar que a ocorrência da murcha na região do estudo apresentou um número menor de focos unitários no povoamento de menor incidência; número reduzido de árvores por foco; maior agregação dos focos, indicando maior agregação e proximidade entre todas as plantas pertencentes ao foco, originando focos com maior comprimento na direção da linha de plantio.

Na parcela estudada, os valores de ICF indicam que a dinâmica espacial da murcha de Ceratocystis em clones de eucalipto tem leve tendência à compactação, numa tendência à agregação dos focos.

\section{Dinâmica espacial - índice de dispersão (ID)}

Os valores de incidência da murcha de Ceratocystis na parcela experimental instalada nas três avaliações realizadas estão apresentados na tabela 2. A cada valor de índice de dispersão foi aplicado o teste do qui-quadrado $\left(\chi^{2}\right)$. Os valores de ID $>1$ foram estimados em ambos os tamanhos de quadrat calculados, sendo o maior valor para a terceira avaliação da parcela experimental, indicando a ocorrência agregada da murcha de Ceratocystis. Tal agregação sugere que a murcha de Ceratocystis é causada por um agente biótico, com alto poder infectivo quando do plantio com materiais suscetíveis no campo, e de rápida e eficaz disseminação, infectando plantas sadias em diferentes direções, sendo preferencialmente no sentido da linha de plantio. Pode-se afirmar também que para a região de estudo o inseto vetor da doença ainda não está presente no ciclo do patógeno devido ao padrão de dispersão apresentado e também pelo fato de não terem sido encontrados vestígios da presença dele nas plantas doentes.

Outras doenças de plantas também apresentaram o mesmo padrão de agregação, tais como a hérnia das crucíferas (33), a ferrugem e o cancro basal do eucalipto $(29,37)$.

Baixa agregação de plantas dentro dos quadrat foi registrada no patossistema citros x ácaro da leprose, em São Paulo (6). Também em citros a dispersão espacial da CVC ocorreu de forma agregada, com focos que envolvem entre nove e quinze plantas $(22,24)$. Nesse estudo, os baixos percentuais de agregação de árvores com murcha obtidos através do índice de dispersão, dentro dos quadrat, devem estar relacionados com a baixa incidência da doença nos povoamentos em 
Tabela 2. Incidência da murcha por Ceratocystis na parcela experimental na região de Três Lagoas/MS; valores do Índice de Dispersão para dois tamanhos de quadrats para parcela experimental em região de Três Lagoas, MS e; valores do teste de $\chi^{2}$ significativos para a agregação da murcha de Ceratocystis.

\begin{tabular}{|c|c|c|c|c|c|}
\hline AVALIAÇÃo & INCIDÊNCIA(\%) & \multicolumn{2}{|c|}{ ÍNDICE DE DISPERSÃO (I.D.) } & \multicolumn{2}{|c|}{$\chi^{2}$ calculado $>\chi^{2}$ tabelado } \\
\hline 1 (janeiro/2009) & 10,77 & 143,38 & 5,19 & 7354 & 109 \\
\hline 2 (agosto/2009) & 13,08 & 114,92 & 4,37 & 9176 & 129 \\
\hline 3 (janeiro/2010) & 25,71 & 383,60 & 13 & 26428 & 351 \\
\hline
\end{tabular}

fases iniciais da cultura.

Foram encontrados materiais com diversos níveis de resistência, desde altamente resistentes até suscetíveis. Os materiais altamente resistentes à doença devem ser submetidos a mais testes de resistência, sendo esses tanto sob condições controladas quanto em campo. Sendo constatada a resistência, esses materiais poderão ser fonte de resistência ao patógeno em programas de melhoramento genético e também utilizados para plantios em áreas onde o patógeno é encontrado.

Para a parcela experimental estudada, a doença apresentou distribuição espacial agregada, com tendência a agregação de focos e distribuição vertical (na linha de plantio). Pode-se afirmar que devido a esse padrão de distribuição espacial o inseto vetor da doença ainda não está inserido no ciclo do patógeno na área estudada.

\section{Agradecimentos}

Os autores agradecem à FAPESP e ao CNPq por concessão de bolsas de estudo sem o qual a realização deste trabalho não seria possível; à Fibria MS pela concessão da área para instalação da parcela experimental e à Duratex pela cessão de material para os testes de resistência.

\section{REFERÊNCIAS BIBLIOGRÁFICAS}

1. ASSOCIAÇÃO BRASILEIRA DE CELULOSE E PAPEL (BRACELPA). Disponível em: 〈http://www.bracelpa.org.br>. Acesso em: 16 fev. 2011.

2. Baker, C. J.; Harrington, T. C.; Krauss, U.; Alfenas, A. C. Genetic variability and host specialization in the Latin American clade of Ceratocystis fimbriata. Phytopathology, Saint Paul, v. 93, n. 10, p. 1274-1284, 2003.

3. Baker, C. J.; Harrington, T. C. Ceratocystis fimbriata. Kew, Surrey: CABI Publishing, 2004. 14 p.

4. Barnes, I.; Roux, J.; Wingfield, B. D.; Dudzinski, M. J.; Old, K. M.; Wingfield, M. J. Ceratocystis pirilliformis, a new species from Eucalyptus nitens in Australia. Mycologia, Corballis, v. 95, n. 5, p. 865-871, 2003.

5. Bassanezi, R. B. et al. Spatial and temporal analyses of citrus sudden death as a tool to generate hypotheses concerning its etiology. Phytopathology, Saint Paul, v. 93, n. 4, p. 502-512, 2003.

6. Bassanezi, R. B; Laranjeira, F. F. Spatial patterns of leprosis and its vector in commercial citrus groves in Brazil. Plant Pathology, Malden, v. 56, p. 97-106, 2007.

7. Bedendo, I. P. Doenças vasculares. In: Amorim, L.; Bergamin Filho, A.; Kimati, H. (Eds.). Manual de fitopatologia: princípios e conceitos. 3. ed. São Paulo: Ceres, 1995. v. 1, p. 838-847.

8. Bergamin Filho, A.; Hau, B.; Amorim, L; Jesus Junior, W. C. Análise espacial de epidemias. In: Vale, F. R.; Jesus Junior, W.C; Zambolim, L. (Eds.). Epidemiologia aplicada ao manejo de doenças de plantas. Belo Horizonte: Perfil, 2004. p. 193-240.
9. Colturato, A.B. Epidemiologia e manejo da seca de ponteiros de Corymbia citriodora (Botryosphaeria ribis/ Dothyorella sp.). 2009. 68 f. Tese (Doutorado em Agronomia/Proteção de Plantas) - Faculdade de Ciências Agronômicas, Universidade Estadual Paulista, Botucatu, 2009.

10. Dominguez, R. P. F.; Velásquez, F. Selección de plantas de cação (Theobroma cacao L.) por resistência al hongo Ceratocystis fimbriata. Revista de la Facultad de Agronomia de la Universidad Central de Venezuela, Maracay, v. 6, n. 1, p. 57-73, 1972.

11. Ferreira, F. A. Constatação rápida de Ceratocystis fimbriata na doença murcha de Ceratocystis em eucalipto por meio de cortes histopatológicos à mão livre. Fitopatologia Brasileira, Brasília, v. 25, p. 372, 2000. Suplemento.

12. Ferreira, F. A.; Murcha de Ceratocystis em eucalipto no Brasil. Fitopatologia Brasileira. Brasília, v. 24, p. 284, 1999. Suplemento.

13. Ferreira, F. A.; Maffia, L. A.; Barreto, R. W; Demuner, N. L.; Pigatto, S. Sintomatologia da murcha de Ceratocystis fimbriata em eucalipto. Revista Árvore, Viçosa, v. 30, n. 2 p. 155-162, 2006.

14. Ferreira, F. A. Patologia florestal: principais doenças florestais no Brasil. Viçosa, Sociedade de Investigações Florestais, 1989. $570 \mathrm{p}$.

15. Ferreira, F. A.; Milani, D. Diagnose visual e controle das doenças abióticas e bióticas do eucalipto no Brasil. Mogi Guaçu: International Paper, 2002. 104 p.

16. Furtado, E. L.; Dias, D.C.; Ohto, C. T.; Rosa, D. D. Doenças do eucalipto e coleta de materiais para análise patológica. Botucatu: Votorantim Celulose e Papel, 2008. 56 p.

17. Gottwald, T. R.; Avinent, L. Analysis in the spatial spread of sharka (plum pox virus) in apricot and peach orchards in eastern Spain. Plant Disease, Saint Paul, v. 79, n. 3, p. 266-278, 1995.

18. Gottwald, T. R.; Cambra, M; Moreno, P; Camarasa, E; Piquer, J. Spatial and temporal analyses of citrus tristeza virus in eastern Spain. Phytopathology Saint Paul, v. 86, n. 1, p. 45-55, 1996.

19. Hughes, G.; Madden, L. V. Aggregation and incidence of disease. Plant Pathology. Malden, v. 41, n. 6, p. 657-660, 1992.

20. Izquierdo, J. E. Comportamiento de genotipos de cafetas ante Ceratocystis fimbriata. Cienc.Tec. Agric. Cafe y Cacao, Turrialba, v. 1, n. 1/2, p. 53-59, 1988.

21. Jesus Junior, W. C.; Bassanezi, R. B. Análise da dinâmica e estrutura de focos da morte súbita dos citros. Fitopatologia Brasileira, Brasília, v. 29, n. 4, p. 399-405, 2004.

22. Laranjeira, F. F. Dinâmica espacial e temporal da clorose variegada dos citros. 1997. Dissertação (Mestrado em Proteção de Plantas) - Escola Superior de Agricultua Luiz de Queiroz, Universidade de São Paulo, Piracicaba, 1997.

23. Laranjeira, F. F.; Amorim, L.; Bergamin Filho, A.; Berger, R. D.; Hau, B. Análise espacial do amarelecimento fatal do dendezeiro como ferramenta para elucidar sua etiologia. Fitopatologia Brasileira, Brasília, DF, v. 23, n. 3, p. 397-403, 1998.

24. Laranjeira, F. F.; Bergamin Filho, A.; Amorim, L.; Gottwald, T. R. Dinâmica espacial da clorose variegada dos citros em três regiões do Estado de São Paulo. Fitopatologia Brasileira, Brasília, v. 29, n. 1, p. 56-65, 2004.

25. Laranjeira, F. F.; Bergamin Filho, A; Amorim, L. Dinâmica e 
estrutura de focos da clorose variegada dos citros (CVC). Fitopatologia Brasileira, Brasília, DF, v. 23, n. 1, p. 36-41. 1998.

26. Machado, P. S.; Ferreira, E. M.; Binoti, D. H. B.; Mafia, R. G.; Alfenas, A. C. Resistência interespecífica de Eucalyptus à murchade-ceratocystis, causada por Ceratocystis fimbriata. Tropical Plant Pathology, Brasília, DF, v. 33, p. 268, 2008. Suplemento.

27. Madden, L. V.; Nault, L. R.; Murral, D. J.; Apelt, M. R. Spatial pattern analysis of the incidence of aster yellows disease in lettuce. Researches on Population Ecology, Kyoto, v. 37, p. 279289, 1995.

28. Madden, L.V.; Hughes, G. Plant disease incidence: distributions, heterogeneity and temporal analysis. Annual Review Phytopathology, Palo Alto, v. 33, p. 529-564, 1995.

29. Masson, M. V. Ferrugem do eucalipto: planejamento evasivo, estimativa de dano e análise da viabilidade do controle químico. 2009. 167 f. Dissertação (Mestrado em Agronomia/Proteção de Plantas) - Faculdade de Ciências Agronômicas, Universidade Estadual Paulista, Botucatu, 2009.

30. Nelson, S. C. A simple analysis of disease foci. Phytopatology, Saint Paul, v. 86, n. 4, p. 332-339, 1996

31. Nelson, S. C. Spatiotemporal distance class analysis of plant disease epidemics. Phytopathology, Saint Paul, v. 85, n. 1. p. 37-43, 1995

32. Nunes, W. M. C.; Machado, M. A.; Corazza-Nunes, M. J.; Furtado, E. L. Dinâmica espacial de foco da clorose variegada dos citros (CVC) avaliada por meio da sintomatologia e serologia. Acta Scientiarum, Maringá, v. 23, n. 5, p. 1215-1219, 2001.

33. Rosa, D.D. Plasmodiophora brassicae X Brassicaceas: Variabilidade genética e patogênica, epidemiologia da doença e efeito de exsudatos radiculares e plantas não brassicaceas no controle. 2010. 100 f. Tese (Doutorado em Agronomia/Pro- teção de Plantas) - Faculdade de Ciências Agronômicas, Universidade Estadual Paulista, Botucatu, 2010.

34. Roux, J.; Wingfield, M. J.; Bouillet, J-P; Wingfield, B. D.; Alfenas, A. C. A serious new wilt disease of eucalyptus caused by Ceratocystis fimbriata in Central Africa. Forest Pathology, Hoboken, v. 30, p. 175-184, 2000.

35. Roux, J.; Wyk, M. van; Hatting, H.; Wingfield, M. J. Ceratocystis especies infecting stem wounds on Eucalyptus grandis in South Africa. Plant Pathology, Malden, v. 53, n. 4, p. 414-421, 2004.

36. Roux, J.; Coutinho, T. A.; Byabashaija, D. M.; Wingfield, M. J. et al. Diseases in plantation Eucalyptus in Uganda. South African Journal of Science. Pretoria, v. 97, n. 1/2, p. 16-18, 2001.

37. Souza, S. E. Dinâmica espaço-temporal e danos do cancro basal em Eucalyptus grandis. 2007. 160 f. Tese (Doutorado em Agronomia/Proteção de Plantas). Faculdade de Ciências Agronômicas, Universidade Estadual Paulista, Botucatu, 2007.

38. Trindade, D. R.; Furtado, E. L. Doenças da seringueira. In: KIMATI, $\mathrm{H}$. et al. (Eds). Manual de fitopatologia: doenças das plantas cultivadas. 3. ed. v.2. São Paulo: Ceres, 1997. p. 628-641.

39. Vanderplank, J. E. Plant diseases: epidemics and control. New York, Academic Press, 1963. 349 p.

40. Zadocks, J.C.; Schein, R.D. Epidemiology and plant disease management. New York: Oxford University Press, 1979, $427 \mathrm{p}$.

41. Zauza, E. A. V.; Alfenas, A. C.; Harrington, T. C.; Mizubuti, E. S.; Silva, J. F. Resistance of Eucalyptus clones to Ceratocystis fimbriata. Plant Disease, Saint Paul, v. 88, n. 7, 2004. p.758-760.

42. Zuluaga, V.; Valencia, A. G.; Gonzalez, J. Contribuicion al estudio de la naturaleza de la resistencia del cafeto a Ceratocystis fimbriata (Ell. \& Haslt.) Hunt. Cenicafe, Chinchiná (Caldas), v. 22, n., p. 43-68, 1971. 